\title{
Extreme Bradycardia and Bradyarrhythmias at Athletes. What will Technology Development Bring as a Help to Diagnosis Them?
}

\author{
Robert Gajda* \\ Center for Sports Cardiology at the Gajda-Med Medical Center, Pułtusk, Poland
}

ISSN: 2577-1914

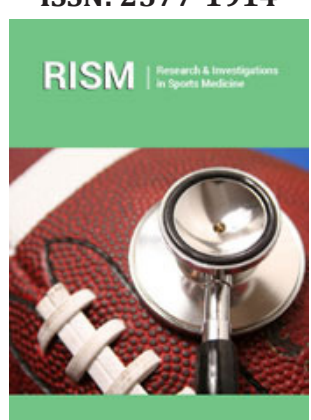

*Corresponding author: Robert Gajda, Center for Sports Cardiology, Gajda-Med Medical Center, Pułtusk, Poland

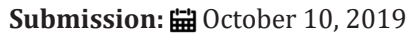

Published: 眥October 24, 2019

Volume 5 - Issue 4

How to cite this article: Robert Gajda. Extreme Bradycardia and Bradyarrhythmias at Athletes. What will Technology Development Bring as a Help to Diagnosis Them? Res Inves Sports Med. 5(4). RISM.000617.2019.

DOI: 10.31031/RISM.2019.05.000617

Copyright@ Robert Gajda, This article is distributed under the terms of the Creative Commons Attribution 4.0 International License, which permits unrestricted use and redistribution provided that the original author and source are credited.
Keywords: Bradycardia, Athletes, Asystolic pauses, Endurance athletes, Pacemaker, AV block

Abbreviations: RBBB: Right Bundle Branch Block; BPM: Beats Per Min; HRMs: Heart Rate Monitors; SCHRM: Strap Chest HRM; OHRM: Optical Heart Rate Monitors; ECG: Electrocardiogram

The morphological and functional cardiac adaptations induced by regular endurance training may be reflected in several athletes' electrocardiographic variants [1]. Rhythm and heart rate disturbances, high QRS voltage, ST segment elevation in the so called "early repolarization," vagotonic or high T wave voltages, first degree AV block, incomplete right bundle branch block (RBBB) are the most common findings. Sinus bradycardia is the most frequent adaptation [2]. A detailed description of the athlete's heart adaptation to effort and most common ECG changes at athletes can be found in numerous papers in the second half of the 20th century [3-5] and an extensive description of athletes' heart ECG is out of the scope of the present chapter. An excellent review of the present interpretation of ECG in athletes and practical recommendations for physicians has been recently published by a recognized group of international experts [6].

Sinus bradycardia is defined as a rhythm lower than 50beats/min (bpm). Frequently observed sinus bradycardia and atrioventricular block at athletes, if asymptomatic, don't require attention, until the pauses don't exceed 4 seconds [7] or, according to other experts, 3 seconds. In fact, in many athletes involved in regular endurance training the heart rate is about $50-60 \mathrm{bpm}$, rarely below $50 \mathrm{bpm}$. Related to the type of sporting activity, 50 to $90 \%$ of athletes show sinus bradycardia with a mean heart rate of $50 \mathrm{bpm}$. Heart rates in the range of 30-40bpm have been observed to vary rarely, mostly in professional cyclists. During night sleep in some elite athletes, very slow heart rates of 25-30bpm have been documented.

A recently published study by French experts revealed that athletes with deep bradycardia do not present more arrhythmias and more hypotensive susceptibility than their nonbradycardic peers. Cardiac enlargement and autonomic alteration both seem to be involved in an athletes' bradycardia [8]. They studied 46 healthy males aged 19-35 with a mean followup of 4.7years. During follow-up no episode of syncope or near syncope was reported.

According to the 36 Bethesda Conference, as far as bradyarrhythmias are concerned, asymptomatic pauses under 3 seconds are likely to be insignificant, while above 3 seconds may be abnormal and require cardiologic evaluation including ECG, Holter monitoring, exercise testing, echocardiography and electrophysiology studies.

In a study performed by Ector et al. [9] athletic patients were examined because of syncope, Stokes-Adams attack or both. Due to the life-threatening condition 7 athletes had pacemakers implanted, another 8 after ceasing to train stopped having clinical symptoms [9].

37 top-ranking athletes underwent $24 \mathrm{~h}$ Holter monitoring. Pauses above 2,5 s. were observed in $19 \%$ athletes as a result of sinus arrest. Second degree AV block was noted in $13 \%$ [9]. A recently published study performed by Senturk et al. [10] was comprised of 194 athletes. 120 of them had cardiac pauses of $1.35-30 \mathrm{sec}$ (!!!). The authors stated that among 
106 athletes with pauses $<3 \mathrm{sec}, 92$ were asymptomatic and 14 were symptomatic. Fourteen athletes had pauses $>3 \mathrm{sec}$, of whom nine were asymptomatic and five were symptomatic. There were no deaths during ca 7.5 years of follow up. The authors conclude that the 3 sec pause threshold does not adequately discriminate between potentially asymptomatic and symptomatic competitive athletes and alone, should not be used to exclude potential competitors.

Polish authors Folga et al. [11] described a case of young, 23year old competitive athlete involved in biathlon endurance training with ECG changes (AV block II degree with Wenckebach periodic) identified by routine medical check-up. In Holter monitoring they identified AV block II degree with many long pauses, the longest with a duration of $6.8 \mathrm{sec}$ in the night during sleep. Because very precise cardiologic diagnostics with ECHO, exercise test and electrophysiological diagnostics did not reveal any pathological changes in this asymptomatic athlete with excellent aerobic capacity, they decided to let him continue his competitive athlete career but under strict cardiological control [11].

Viitasalo et al. [12] analyzed data from Holter ECG in 35 highly trained endurance athletes and in 35 non-athletic controls of similar ages are given Thirteen athletes (37.1\%) but only two controls (5.7\%) had sinus pauses exceeding 2.0 seconds. 13 athletes $(37.1 \%)$ were diagnosed with first degree A-V block and five controls (14.3\%), Wenckebach II-type block in eight athletes (22.9\%) and two controls (5.7\%), and second-degree block with Mobitz II-like pattern in three athletes (8.6\%) and no control. First degree and Wenckebach second type degree A-V block were observed in all athletes with Mobitz II-type pattern. Seven athletes were diagnosed with atrioventricular dissociation with junctional rhythm (20\%), and one with ventricular rhythm. Neither of these phenomena was seen in the group of controls [4].

Northcote et al. [13] described ECG findings in male veteran endurance athletes. Twenty male veteran endurance runners and 20 controls underwent resting, exercise, and ambulatory electrocardiography. The PR interval was observed to be longer in the athletes, along with longer mean (SD) treadmill exercise times (19 (4) v 16 (2) min) when compared to the controls. A consistently lower heart rate was observed in the athletes during $48 \mathrm{H}$ Holter ECG. In eight athletes but only one control profound bradycardia $(<35 \mathrm{bpm})$ was observed. Asystolic pauses lasting from 1.8 to 15 seconds were observed in 8 athletes and 2 controls. First degree heart block was recognized in 6 athletes, Mobitz II second degree block in 4 , and complete heart block in 3 . The majority of conduction abnormalities appeared at night and retreated during exercise. Ventricular ectopic activity was not significantly different between the groups. Thus, heart block patterns and profound bradycardia are more frequent in older athletes than their youthful counterparts [13].

Today's millions of physically active individuals worldwide use heart rate monitors (HRMs) to control their exercise intensity. In many cases, the HRM indicates an unusually high heart rate (HR) or even arrhythmias during training [14]. Heart rate monitors are used for runners, cyclists, swimmers as well as competitors of many other disciplines including Mountaineering and sailing [15]. HRMs have been designed for use by healthy athletes with a baseline sinus rhythm, but they have also captured exercise-induced arrhythmia in this bradyarrhythmias or bradycardia. Future studies verifying the value of newly developed mobile devices, such as ECG Patch Monitoring or Time Smart Phone Monitoring, Injectable Loop Recorders, Device-tailored monitors and other devices, in diagnosing exercise-induced arrhythmias and bradyarrhythmias. Author of this article almost every day in Center for Sports Cardiology in Pułtusk (Poland) have contact with athletes, who observe bradyarrhythmias or most often night bradycardia on their typical strap chest HRM (SCHRM) or some time optical heart rate monitors (OHRM) and other devices like bracelet with apps on their mobile to control HRM. Holter ECG made in these people, very often confirm not only bradycardia but various bradyarrhythmias, including atrioventricular blocks.

What will technology development bring athletes and doctors together as a help to diagnosis bradyarrhythmias? There will surely be better and more accurate devices. HRMs are not medical devices for arrhythmia detection. They were created for another purpose - training control. But it's just a matter of technical solutions that instead of the average heart rhythm record, there will also be the complete record, which will be the usual ECG curve (electrocardiogram). And this is a device with a high diagnostic value for the medical profession used by athletes. In fact, such devices are already on the market [16].

\section{References}

1. Bjørnstad HH, Bjørnstad TH, Urheim S, Hoff PI, Smith G, et al. (2009) Long-term assessment of electrocardiographic and echocardiographic findings in Norwegian elite endurance athletes. Cardiology 112(3): 234241.

2. D'Souza A, Sharma S, Boyett MR (2015) CrossTalk opposing view: Bradycardia in the trained athlete is attributable to a downregulation of a pacemaker channel in the sinus node. J Physiol 593(8): 1749-1751.

3. Hanne-Paparo N, Kellermann JJ (1981) Long-term Holter ECG monitoring of athletes. Med Sci Sports Exerc 13(5): 294-298.

4. Viitasalo MT, Kala R, Eisalo A (1982) Ambulatory electrocardiographic recording in endurance athletes. Br Heart J 47(3): 213-220.

5. Boraita Pérez A, Serratosa Fernández L (1998) The athlete's heart: Most common electrocardiographic findings. Rev Esp Cardiol 51(5): 356-368.

6. Drezner JA, Sharma S, Baggish A, Papadakis M, Wilson MG, et al. (2017) International criteria for electrocardiographic interpretation in athletes: Consensus statement. Br J Sports Med 51(9): 704-731.

7. Zehender M, Meinertz T, Keul J, Just H (1990) ECG variants and cardiac arrhythmias in athletes: Clinical relevance and prognostic importance. Am Heart J 119(6): 1378-1391.

8. Matelot D, Schnell F, Khodor N, Endjah N, Kervio G, et al. (2016) Does deep bradycardia increase the risk of arrhythmias and syncope in endurance athletes? Int J Sports Med 37(10): 792-798.

9. Ector H, Bourgois J, Verlinden M, Hermans L, Vanden Eynde E, et al. (1984) Bradycardia, ventricular pauses, syncope, and sports. Lancet 2(8403): 591-594.

10. Senturk T, Xu H, Puppala K, Krishnan B, Sakaguchi S, et al. (2016) Cardiac pauses in competitive athletes: A systematic review examining the basis of current practice recommendations. Europace 18(12): 1873-1879. 
11. Folga A, Braksator W, Mamcarz A (2010) Pauses In athlete-is it still a norm? Folia Cardiologica Exerpta 5(Suppl A): 24-26 (in Polish).

12. Viitasalo MT, Kala R, Eisalo A (1984) Ambulatory electrocardiographic findings in young athletes between 14 and 16 years of age. Eur Heart J 5(1): 2-6.

13. Northcote RJ, Canning GP, Ballantyne D (1989) Electrocardiographic findings in male veteran endurance athletes. Br Heart J 61(2): 155-160.

14. Gajda R, Biernacka EK, Drygas W (2018) Are heart rate monitors valuable tools for diagnosing arrhythmias in endurance athletes? Scand J Med Sci Sports 28(2): 496-516.
15. Gajda R, Kowalik E, Rybka S, Rębowska E, Śmigielski W, et al. (2019) Evaluation of the heart function of swimmers subjected to exhaustive repetitive endurance efforts during a 500-km relay. Front Physiol 10: 296.

16. Gajda R, Biernacka EK, Drygas W (2018b) “The problem of arrhythmias in endurance athletes: are heart rate monitors valuable tools for diagnosing arrhythmias?", Horizons in World Cardiovascular Research. Nova Science Publishers, New York, USA 15: 1-64.

For possible submissions Click below: 